\title{
Studi Inventarisasi Serangan Hama Pada Karet Alam (Hevea brasilliensis) Di Desa Baras Kecamatan Dedai Kabupaten Sintang
}

\author{
Antonius \\ Fakultas Pertanian Universitas Kapuas Sintang \\ e-mail: anton1975_gurung@yahoo.co.id
}

\begin{abstract}
Abstrak: Penelitian ini bertujuan untuk mengetahui jenis-jenis hama yang mengganggu atau merusak tanaman karet alam dan untuk mengetahui bagianbagian tanaman karet alam yang diserang oleh hama di wilayah Desa Baras Kecamatan Dedai. Metode yang digunakan adalah metode inventarisasi dan identifikasi hama yang menyerang tanaman karet alam. Hasil penelitian menunjukkan bahwa Jenis Hama pada tanaman karet alam yang sering terjadi adalah hama Rayap (Microternes inspiratus), Tikus (Rattus sp), Tupai (Callosciurus notatus), Babi (Sus venrrucosus), Kijang (Muntiacus muntjak) dan Rusa (Rusa timorensis). Serangan hama Rayap (Microternes inspiratus) pada akar hingga pucuk tanaman, Tikus (Rattus sp) menyerang kulit batang dan daun muda, Tupai (Callosciurus notatus) menyerang kulit batang, dahan dan daun serta buah, Babi (Sus venrrucosus) menyerang kulit batang dan daun serta membongkar tanah disekeliling tanaman karet, Kijang (Muntiacus muntjak) menyerang kulit batang dan daun dan Rusa (Rusa timorensis) menyerang kulit batang dan daun.
\end{abstract}

Kata Kunci: Hama, Karet Alam

\section{PENDAHULUAN}

Usaha perkebunan karet

( Havea brasilliensis ) memainkan peran yang cukup penting bagi perekonomian Negara Indonesia. Negara ini merupakan Negara produsen karet alam kedua terbesar di dunia setelah Tailand. Pada tahun 2006, produksi karet alam mencapai 2,46 juta ton, lebih dari $90 \%$ nya ( 2,45 juta ton ) adalah jenis crumb rubber di seluruh Indonesia. Industri crumb rubber ( karet remah ) memiliki arti yang sangat penting bagi perolehan devisa sekaligus penyerapan tenaga kerja. Sebagai gambaran pada tahun 2006, industri crumb rubber berhasil meraup devisa ekspor senilai US\$ 3,77 Milyar, hampir 50\% dari nilai ekspor produk pertanian (Anonim, 1991). Tenaga kerja yang terserap di bidang produksi crumb rubber mencapai + 100.000, sedangkan di bidang penyedian bahan baku (petani karet) lebih dari 6 juta orang, belum termasuk para pedagang pengumpul. Luas areal tanaman Karet di 
Indonesia pada saat ini 3,309 juta ha, dimana $84,49 \% \quad(2,796$ ha $)$ merupakan perkebunan rakyat (Anonim, 2006). Oleh karena itu maju mundurnya kinerja industri karet alam di dalam negeri akan memberikan dampak yang cukup luas bagi kesejahtraan rakyat.

Peluang yang cerah bagi perkaretan nasional tentunya bisa di raih jika Indonesia mampu meningkatkan kinerja agroindustri karetnya, antara lain melalui peningkatan mutu crumb rubber, dan peningkatan nilai produk menjadi barang jadi. Oleh karena itu sebagai tanaman penghasil lateks tanaman karet dapat dikatakan satu-satunya tanaman yang di kebunkan secara besar-besaran ( Nazarudin dkk,1992 ) .

Kendala yang dialami oleh masyarakat terutama diwilayah Desa Baras Kecamatan Dedai, didalam pembudidayaan Karet alam ini. Kendala tersebut antara lain terganggunya tanaman Karet alam oleh serangan hama. Hama akan mengganggu pertumbuhan dan perkembangan karet dari tingkat semai hingga siap panennya. Oleh karena seringnya terjadi serangan hama pada karet alam ini yang membuat banyak kerugian bagi petani karet khususnya di wilayah Desa Baras Kecamatan Dedai.

Hingga saat ini masih banyak masyarakat yang belum mengetahui secara pasti mengatasi serangan hama yang menyerang tanaman karet alam dan jenis -jenis hama apa saja yang sering terjadi. Hal ini di sebabkan karena kurangnya pengetahuan masyarakat akan bagaimana cara memelihara karet alam dengan baik di tambah kurang profesionalnya masyarakat di dalam mengelola tanaman karet ini. Kurangnya pengetahuan masyarakat tentang budidaya tanaman karet yang intensif seperti kegiatan pemupukan dan pemberantasan gulma yang mengakibatkan menurunnya produktivitas hasil panen lateks pada karet yang di budidayakannya, selain itu tanaman karet juga mudah mengalami serangan hama.

\section{METODOLOGI PENELITIAN}

Penelitian ini dilakukan dengan menggunakan metode survey, dengan melakukan inventarisasi 
terhadap serangan hama pada tanaman karet alam. Metode survey dilakukan pada areal perkebunan karet alam, pengamatan dilakukan pada tanaman karet muda hingga karet tua.

Pengamatan dilakukan pada petak-petak yang telah ditentukan (purposive sampling) pada areal di temukannya tanaman karet yang terserang hama. Bentuk petak pengamatan berukuran $100 \mathrm{~m}$ x 100 $\mathrm{m}$, sebanyak 3 (tiga) petak pengamatan. Hasil survey melalui inventarisasi dan identifikasi jenis hama selanjutnya ditabulasi dan di diskripsikan.

\section{HASIL DAN PEMBAHASAN}

Tingkat

pemahaman masyarakat akan teknis budidaya karet sangat mempengaruhi kualitas maupun kuantitas pertumbuhan tanaman karet, teknis budidaya yang kurang baik, misalnya semak belukar yang tidak dibersihkan akan menjadi penyebab mudahnya tanaman karet mengalami serangan berbagai hama. Hama yang menyerang tanaman karet alam dapat terjadi mulai dari serangan pada akar, batang, daun dan bahkan dahan. Berikut jenis hama serta bagian tanaman yang banyak diserang pada tanaman karet alam.

Tabel 4.1. Jenis Hama dan Bagian Yang Diserang Pada Tanaman Karet alam

\begin{tabular}{|l|l|l|l|}
\hline No. & Jenis Hama & Nama Latin & Bagian Yang Diserang \\
\hline 1 & Rayap & Microternes inspiratus & $\begin{array}{l}\text { Rayap merupakan jenis serangga tanah } \\
\text { yang menyerang tanaman karet pada } \\
\text { berbagai tingat umur. Rayap } \\
\text { menyerang kulit batang lalu memakan } \\
\text { getah karet, bila tidak diobati maka } \\
\text { lama kelamaan karet mati karena } \\
\text { kehabisan getahnya. }\end{array}$ \\
\hline 2 & Tupai & Callosciurus notatus & $\begin{array}{l}\text { Tupai sejenis hewan yang hidup di } \\
\text { atas pohon, biasanya tupai menggigit } \\
\text { dahan/cabang tanaman karet } \\
\text { sepanjang cabang yang } \\
\text { mengakibatkan getah karet menetes } \\
\text { dari cabang yang dilukai. Karet yang } \\
\text { diserang oleh hama Tupai tidak } \\
\text { sampai menimbulkan kematian, } \\
\text { namun memudahkan karet terserang } \\
\text { jamur pada musim penghujan. }\end{array}$ \\
& & & $\begin{array}{l}\text { Tikus termasuk kelompok hewan } \\
\text { pengerat yang sering menyerang } \\
\text { tanaman muda, namun hama tikus }\end{array}$ \\
\hline 3 & Tikus & Rattus $\mathrm{sp}$ &
\end{tabular}




\begin{tabular}{|c|c|c|c|}
\hline & & & $\begin{array}{l}\text { tidak terlalu membahayakan bagi } \\
\text { tanaman karet, karena intensitas } \\
\text { serangan relatif sedikit dan tidak } \\
\text { menimbulkan kematian bagi tanaman. }\end{array}$ \\
\hline 4 & Babi & Sus venrrucosus & $\begin{array}{l}\text { Babi merupakan hewan yang suka } \\
\text { merusak tanah di sekitar tanaman, } \\
\text { sehingga tanaman karet muda akan } \\
\text { tumbang namun tidak dimakan. } \\
\text { Apabila Babi dalam jumlah banyak, } \\
\text { maka sering menimbulkan kerusakan } \\
\text { yang cukup berarti karena tanaman } \\
\text { karet muda banyak yang tercabut dan } \\
\text { mati. }\end{array}$ \\
\hline 5 & Kijang & Muntiacus muntjak & $\begin{array}{l}\text { Kijang merupakan hewan pemakan } \\
\text { daun karet, bila karet masih kecil dan } \\
\text { daunnya terjangkau, maka kerusakan } \\
\text { pada daun banyak terjadi. Akibat daun } \\
\text { ditarik maka tanaman sering patah } \\
\text { sehingga mengakibatkan tanaman sulit } \\
\text { untuk tumbuh dengan baik. }\end{array}$ \\
\hline 6 & Rusa & Rusa timorensis & $\begin{array}{l}\text { Rusa merupakan hewan pemakan daun } \\
\text { karet sebagaimana hewan jenis Kijang } \\
\text { Rusa menyerang tanaman karet yang } \\
\text { sudah cukup besar namun masih } \\
\text { mampu dipatahkan. Untuk tanaman } \\
\text { karet muda, maka serangan terjadi } \\
\text { pada daun. Namun untuk karet yang } \\
\text { sudah cukup besar serangan dengan } \\
\text { cara mematahkan batang tanaman } \\
\text { karet selanjutnya memakan daun } \\
\text { tanaman karet yang sudah dipatahkan }\end{array}$ \\
\hline
\end{tabular}

Sumber: Hasil Penelitian, Tahun 2019

Berdasarkan data hasil penelitian pada tabel di atas terlihat bahwa jenis hama yang menyerang tanaman karet alam ditemukan sebanyak 6 (enam) jenis hama. Dari jenis-jenis hama tersebut berpotensi menimbulkan kegagalan budidaya pada tanaman karet alam.

Sistem budidaya karet alam lokal milik masyarakat merupakan sistem budidaya karet tanam tinggal, dimana setelah karet dari bibit seedling (anakan) ditanam pada bekas ladang setelah panen padi dilakukan, selanjutnya ditinggal tanpa pemeliharaan sehingga keberhasilan untuk hidup relatif rendah. Tanaman karet tumbuh diantara semak belukar, menunjukkan bahwa karet tersebut kurang mendapatkan perawatan yang memadai. Hal ini salah satu pemicu 
Studi Inventarisasi Serangan Hama Pada Karet Alam (Hevea brasilliensis)

Di Desa Baras Kecamatan Dedai Kabupaten Sintang

mudahnya tanaman karet alam mengalami serangan berbagai jenis hama.

\section{Rayap}

Klasifikasi rayap menurut Kalshoven (1981), masuk ke dalam Kingdom Animalia, Phylum Arthropoda,Class Insecta, Ordo Isoptera, Family Rhinotermitidae dan Termitidae, Genus Coptotermes dan Microtermes, Species Coptotermes curvignathus Holmgr. dan Microtermes inspiratus Kemn.

Rayap hidup dalam bentuk koloni sebagai serangga sosial. Sebuah koloni dapat beranggotakan ratusan hingga jutaan individual. Bersarang di atas maupun di bawah tanah pada batang pohon tanaman karet yang mati dan banyak menyerang tanaman karet dengan sifat serangannya yang meluas. Pada perkebunan karet hama ini menyerang tanaman baru tanam (TBM) maupun tanaman yang sudah disadap. Coptotermes dan Microtermes dapat dibedakan berdasarkan ukuran dan daya rusak terhadap serangganya.
Pada umumnya rayap mulai menyerang tanaman karet dari akar yang mati serta pangkal kayu yang ada di sekitar batang karet. Adanya gerekan pada batang dari ujung sampai ke akar dan memakan akar. Biasanya pada kebun yang terserang JAP (Jamur akar putih) akan diiringi dengan serangan rayap sehingga mempercepat tanaman mati. Pengendalian hama rayap dapat dilakukan dengan cara membangun kebun yang bersih dan dapat dilakukan dengan cara kimiawi melalui pemberian Furadan.

\section{Tupai}

Tupai (Callosciurus notatus) sering menyerang tanaman karet dengan gejala serangan seperti batang tanaman muda tampak terkerat secara spot-spot maupun melingkar seperti spiral.

Serangan hama Tupai terhadap tanaman karet lokal sering terjadi pada bagian batang dan dahan, sehingga menyebabkan pertumbuhan batang terhadap dan kulit sukar disadap. Akibatnya produksi lateks menurun karena terserang hama Tupai. Umumnya karet yang 
terserang yang keberadaannya dekat dengan hutan dan semak belukar.

Pengendalian serangan hama tupai dapat dilakukan dengan berbagai cara, antara lain dengan cara kultur teknis, mekanis dan kimiawi. Secara kultur teknis, yaitu dengan cara kebun karet dibersihkan dsari semak belukar dan tanaman penutup tanah dipelihara dengan baik.

\section{Tikus}

Tikus (Rattus sp) merupakan hama tanaman karet yang biasa menyerang atau memakan biji, kecambah, dan daun bibit. Kulit batang tanaman muda terkelupas karena digigit. Tikus yang hidup dengan membuat lubang di dalam tanah menyebabkan sulitnya untuk membasminya.

Hama tikus dapat dikendalikan secara kultur teknis, mekanis dan kimiawi. Lebih lanjut (Anonimous, 2008) menyatakan bahwa pengendalian hama tikus secara kultur teknis yaitu dengan cara membersihkan kebun karet dari semak belukar. Secara mekanis, sarang tikus dibongkar dan tikus ditangkap serta dibunuh. Selain itu, secara mekanis dapat dilakukan dengan memasang perangkap tikus yang telah diberi umpan agar tikus masuk perangkap. Sedangkan pengendalian secara kimia dapat dilakukan dengan cara di racun dengan racun tikus merek dagang Racumin, Warfarin, Tomorin dengan dosis $1 \mathrm{gr} / 15 \mathrm{gr}$ umpan. Umpan yang biasa digunakan berupa beras, jagung, ubi, ikan asin.

\section{Babi}

Babi (Sus venrrucosus) merupakan hama bagi tanaman karet, baik babi peliharaan maupun babi hutan mempunyai daya rusak yang sama. Dimana kebiasaan masyarakat di sekitar hutan memelihara babi dengan cara di lepas, sehingga merusak tanaman budidaya, diantaranya adalah tanaman karet. Gejala serangan dengan ciri-ciri daun tanaman karet yang masih muda tidak berbentuk, bahkan daun ada yang habis, kulit dan batang tanaman muda tampak terkerat dan tanah disekeliling tanaman terbongkar.

Serangan hama babi dapat dikendalikan dengan berbagai cara, antara lain dengan cara membunyikan atau memukul 
kentungan disekitar kebun dan dengan cara membersihkan kebun dari semak belukar. Perkebunan yang dekat dengan hutan harus dibersihkan dari semak belukar agar tidak menjadi tempat ham bersarang atau bersembunyi.

\section{Kijang dan Rusa}

Kijang (Muntiacus muntjak)

dan Rusa (Rusa timorensis) merupakan dua jenis hewan yang memiliki kesamaan dalam menyerang tanaman karet. Perbedaannya kedua jenis binatang ini memiliki bobot badan yang berbeda, Kijang memiliki bobot badan yang jauh lebih kecil dibandingkan dengan Rusa. Gejala serangan memiliki kesamaan, yaitu memakan daun tanaman karet yang bisa diambilnya, dan batang tampak bekas gigitan binatang dengan cara digigt atau ditanduk.

Rusa dan Kijang biasanya memakan daun tanaman karet hingga tanaman karet mati akibat racun dari air liur binatangini. Tanaman biasanya mati bila kulit disekeliling batang habis digerogoti. Kebun yang sering mendapat serangan berat biasanya pada kebun yang berbatasan langsung dengan hutan atau semak belukar.

Pengendalian dapat dilakukan dengan cara diusir atau dihalau, seperti membunyikan kentungan, diburu dengan anjing pemburu, dipasang orang-orangan disekitar kebun, memasang ter dengan cara dioles tipis pada kulit batang yang mudah terserang, dan kebun karet disekitar harus dibersihkan dari semak belukar. Kebun yang bersih tidak mudah diserang oleh hama binatang.

\section{KESIMPULAN DAN SARAN}

\section{Kesimpulan}

1. Jenis Hama pada tanaman karet lokal yang sering terjadi adalah hama Rayap (Microternes inspiratus), Tikus (Rattus sp), Tupai (Callosciurus notatus), Babi (Sus venrrucosus), Kijang (Muntiacus muntjak) dan Rusa (Rusa timorensis).

2. Serangan hama Rayap (Microternes inspiratus) pada akar hingga pucuk tanaman, Tikus (Rattus sp) menyerang kulit batang dan daun, Tupai 
Studi Inventarisasi Serangan Hama Pada Karet Alam (Hevea brasilliensis) Di Desa Baras Kecamatan Dedai Kabupaten Sintang

(Callosciurus notatus)

menyerang kulit batang, dahan dan daun, Babi (Sus venrrucosus) menyerang kulit batang dan daun serta membongkar tanah disekeliling tanaman karet, Kijang (Muntiacus muntjak) menyerang kulit batang dan daun dan Rusa (Rusa timorensis) menyerang kulit batang dan daun.

\section{Saran}

Untuk mencegah terjadinya serangan hama pada tanaman karet alam dapat dilakukan dengan menjaga kebersihan kebun, kebun yang selalu bersih membuat hama tidak menyukai tempat tersebut, sehingga tanaman karet alam terhindar dari serangan hama.

\section{DAFTAR PUSTAKA}

Anonim, Laporan Tahunan 2006 Lembaga Riset Perkebunan Indonesia (Pusat Penelitian Karet, 2006).

$\begin{array}{llr}\text { Anonim, } & \text { "Sekilas } & \text { Catatan } \\ & \text { Komuditas } & \text { Karet } \\ \text { Indonesia } & \text { Tahun } \\ & \text { 1988", Sasaran, No. } \\ \text { 14, Jakarta, 1989. }\end{array}$

Anonim, “ Siapa Produsen Terbesar Karet Alam Dunia di Tahun 2000 nanti" Sasaran, No. 26, 1991.

Anonim, “ Empat Puluh Lima Ribu Hektar Kebun Karet Terserang Penyakit Gugur Daun", Suara Karya, 26 September 1991.

$\begin{array}{lrr}\text { Anonim, } & \text { Tanaman } & \text { Karet } \\ & \text { Indonesia } & \text { Kini } \\ & \text { Terancam } & \text { Penyakit } \\ & \text { Hawar } & \text { Daun", } \\ & \text { Kompas, } & 12 \\ & \text { September } 1991 .\end{array}$

Aidi-Daslin, 1995. Pengelolaan

Bahan Tanaman

Karet. Pusat

Penelitian Karet.

Balai Penelitian

Sumbawa. Palembang.

Anwar, Chairil. 2006. Manajemen dan Teknologi Budidaya Karet. Makalah Pelatihan “ Tekno Ekonomi Agribisnis Karet”, 18 Mei 2006. Jakarta.

Anwar, Chairil. 2001. Manajemen dan Teknologi Budidaya Karet. Pusat Penelitian Karet. Medan.

Anwar, Chairil. 2006. Perkembangan Pasar dan Prospek Agribisnis Karet di Indonesia. Prosiding Lokakarya Budidaya 
Studi Inventarisasi Serangan Hama Pada Karet Alam (Hevea brasilliensis) Di Desa Baras Kecamatan Dedai Kabupaten Sintang

Tanaman Karet. Pusat Penelitian Karet.

Gaon, Loo Thio. 1980. Tuntunan Praktis Untuk Mengelola Karet Alam Khusus Untuk Petani Kecil dan Menengah. Jakarta. PT. Kinta. 163 hal.

Ikandar, S.H. Pengantar Budidaya Karet. Program Diploma I. Jurusan PLPT PerkebunanIPB. Bogor. 1983.

Joesi Endah, Ir. \& Ir. Novizan. 2003. Mengendalikan Hama dan Penyakit Tanaman. Jakarta. Agromedia Pustaka.

Karyudi, Indraty, Suharyanti dan Sudiharto. 2003. Teknologi Budidaya Karet Untuk Daerah Kering di Kawasan Timur Indonesia. Prosiding Konfrensi Karet Menunjang Industri Lateks dan Kayu. Pusat Penelitian Karet. 11 Hal.

Kalshoven, L. G. E., 1981. Pests Of Crops in Indonesia. P.T.
Ichtiar Baru-Van Hoeve. Jakarta.

Nur Tjahyadi, Ir. 1989. Hama dan Penyakit tanaman. Yogyakarta. Kanisius Media.

Parhusip, adhy Basar. Potret Karet Alam Indonesia. Economik Review No. 213. September 2008.

Pusat Penelitian Karet. 2003. Sapta Bina Usaha Tani karet Rakyat. Balai Penelitian Sembawa. Pusat Penelitian Karet. 148 Hal.

Setiawan, H. D dan Andoko, A. 2005. Petunjuk Lengkap Budidaya Karet. Agromedia Pustaka. Jakarta.

Spillane, J. 1989. Komoditi Karet : Peranannya dalam Perekonomian Indonesia. Yogyakarta. Kanisius. 218 Hal. 